\title{
Kinetic and functional analysis of the small RNA methyltransferase HEN1: The catalytic domain is essential for preferential modification of duplex RNA
}

\author{
GIEDRIUS VILKAITIS, ${ }^{1}$ ALEXANDRA PLOTNIKOVA, ${ }^{1}$ and SAULIUS KLIMAŠAUSKAS \\ Laboratory of Biological DNA Modification, Institute of Biotechnology, LT-02241 Vilnius, Lithuania
}

\begin{abstract}
The HEN1 RNA methyltransferase from Arabidopsis thaliana catalyzes S-adenosyl-L-methionine (AdoMet)-dependent 2'-O-methylation at the 3'-termini of small double-stranded RNAs and is a crucial factor in the biogenesis of plant small noncoding RNAs, such as miRNAs or siRNAs. We performed functional and kinetic studies of the full-length HEN1 methyltransferase and its truncated form comprising the C-terminal part of the protein (residues 666-942) with a variety of model RNA substrates. Kinetic parameters obtained with natural RNA substrates indicate that HEN1 is highly catalytically efficient in the absence of any supplementary proteins. We find that the enzyme modifies individual strands in succession leading to complete methylation of an RNA duplex. The rates of methyl group transfer to individual strands of hemimethylated substrates under single turnover conditions are comparable with the multiple turnover rate under steady-state conditions, suggesting that release of reaction products is not a rate-limiting event in the reaction cycle. The truncated protein, which includes conserved motifs characteristic for AdoMet binding, efficiently modifies double-stranded RNA substrates in vitro; however, in contrast to the full-length methyltransferase, it shows weaker interactions with both substrates and is sensitive to base mispairing in the first and second positions of the RNA duplex. Our findings suggest an important role for the $\mathrm{N}$-terminal domains in stabilizing the catalytic complex and indicate that major structural determinants required for selective recognition and methylation of RNA duplexes reside in the C-terminal domain.
\end{abstract}

Keywords: microRNA; siRNA; RNA modification; 2'-O-ribose methylation; enzyme kinetics; methyltransferase

\section{INTRODUCTION}

RNA interference plays important roles in modulating gene expression via mRNA depletion or repression of translation (Ghildiyal and Zamore 2009; Moazed 2009). Numerous small noncoding RNAs involved in post-transcriptional gene silencing have been identified and classified based on their structural features, biogenesis pathways, or interactions with cellular proteins. Among such RNA types are 21-24-nucleotide (nt) double-stranded microRNAs (miRNAs) and small interfering RNAs (siRNAs), which are produced from large precursor RNAs via nucleolytic action of the ribonuclease type III enzymes; the guide strand of mature miRNA or siRNA du-

\footnotetext{
${ }^{1}$ These authors contributed equally to this work.

Reprint requests to: Giedrius Vilkaitis, Laboratory of Biological DNA Modification, Institute of Biotechnology, LT-02241 Vilnius, Lithuania; e-mail: giedrius@ibt.lt; fax: (370 5) 2602116.

Article published online ahead of print. Article and publication date are at http://www.rnajournal.org/cgi/doi/10.1261/rna.2281410.
}

plexes interacts with Ago proteins to furnish the core of the RNA-induced silencing complex (RISC) (Carthew and Sontheimer 2009). In the cell, miRNAs regulate the expression of protein-coding genes, while siRNAs are typically involved in silencing of genes and transposons apart from direct antivirus immune response (Wang et al. 2006; Bartel 2009; Carthew and Sontheimer 2009; van Rij and Berezikov 2009). Another type of small silencing RNAs is represented by 24-31-nt-long piRNAs, which participate in germ cell maintenance (Kim et al. 2009). In contrast to miRNAs and siRNAs, biogenesis of piRNAs involves neither Dicer cleavage, nor formation of double-stranded RNA (dsRNA) species (Vagin et al. 2006). Another distinctive feature of piRNAs is their cellular interactions with the Piwi subfamily of Argonaute proteins (Piwi, Aubergine, Ago3) (Brennecke et al. 2007; Gunawardane et al. 2007).

Biogenesis of miRNAs and siRNAs in plants involves methylation of Dicer-processed double-stranded RNA molecules. This step is catalyzed by the small RNA methyltransferase 
HEN1 (Yu et al. 2005). The methylation is critical for microRNA stability in Arabidopsis since the abundance of mature miRNAs in hen1 mutants is greatly reduced (Park et al. 2002). It was thus proposed that methylation protects miRNAs from the 3 '-uridinylation and subsequent recognition by the exonucleolytic machinery (Yu et al. 2005; Yang et al. 2006). Unlike those of plants, animal microRNAs typically lack the 3 '-terminal modifications. However, piRNAs of vertebrates and insects (Horwich et al. 2007; Houwing et al. 2007; Kirino and Mourelatos 2007b; Ohara et al. 2007; Saito et al. 2007), conjugation-specific scnRNAs from Tetrahymena (Kurth and Mochizuki 2009), as well as miRNAs and siRNAs associated with Argonaute 2 are methylated at their $3^{\prime}$-ends in vivo (Saito et al. 2007). HEN1 homologs from Tetrahymena, Drosophila, and mouse append methyl group onto piRNA in vitro (Horwich et al. 2007; Kirino and Mourelatos 2007a; Saito et al. 2007). Interestingly, the plant HEN1 prefers miRNA and siRNA duplexes, while the piRNA methyltransferases modify single-stranded RNAs.

To date, HEN1 is the sole characterized RNA-modifying enzyme that catalyzes S-adenosyl-L-methionine (AdoMet)dependent 2'-O-methylation of the $3^{\prime}$-terminal nucleotides in small double-stranded RNAs. No sequence specificity by HEN1 has so far been noted, but rather the length of a RNA duplex (typically 21-24 nt) and the presence of dinucleotide 3 '-overhangs have been defined as important discriminatory factors (Yang et al. 2006). However, little is known about the kinetic and catalytic mechanisms of the reaction. Sequence analyses of HEN1 show two double-stranded RNA-binding domains (dsRBD1 and dsRBD2) and an Latype winged helix-turn-helix motif in the $\mathrm{N}$-terminal part, along with the C-terminal Rossman-fold-like region that includes conserved motifs typical for AdoMet-binding proteins (Fig. 1; Tkaczuk et al. 2006; C Venclovas, pers. comm.). Recent crystal structures of the HEN1 methyltransferase in complex with RNA and the cofactor provided important structural insights into the domain architecture and possible contribution of interacting regions to substrate recognition and catalysis (Huang et al. 2009). However, the exact roles

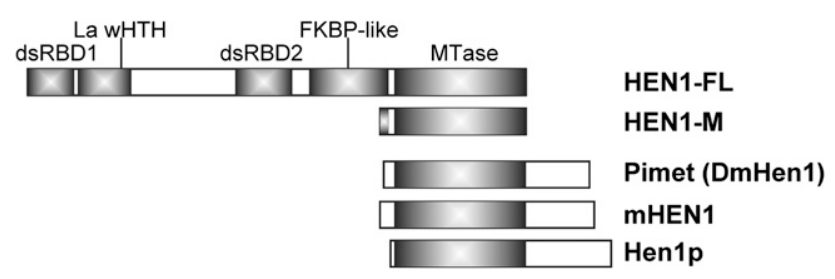

FIGURE 1. Schematic representation of eukaryotic small RNA 2'-O-methyltransferases. HEN1-FL, full-length small RNA methyltransferase from $A$. thaliana; HEN1-M, truncated variant (residues 666-942) of HEN1; Pimet (synonym DmHen1) and mHEN1 are piRNA methyltransferases from Drosophila and Mus musculus, correspondingly; Henlp is scnRNA methyltransferase from Tetrahymena. dsRBD, double-stranded RNA binding domain; La wHTH, La-type winged helix-turn-helix motif; FKBP-like, FK506 binding protein-like domain; MTase, methyltransferase domain. of individual domains in HEN1 still await experimental examination.

Here we report the first steady-state and pre-steady-state kinetic study of HEN1 and a thorough analysis of its interactions with individual strands in dsRNA. We also demonstrate the capability of an isolated C-terminal domain (residues 666-942) to act as an independent catalytic unit and delineate contributions of the $\mathrm{C}$-terminal and $\mathrm{N}$-terminal domains in substrate recognition and catalysis.

\section{RESULTS}

\section{Construction and purification of HEN1 variants}

Two tagged variants of the full-length HEN1 protein have been constructed and purified. The recombinant His-HEN1FL containing an $\mathrm{N}$-terminal (His) ${ }_{6}$ tag was expressed in Escherichia coli and purified by $\mathrm{Ni}^{2+}$-Sepharose affinity chromatography (Yang et al. 2007). To achieve minimal nuclease contamination in HEN1 preparations for certain experiments, we have also constructed a full-length HEN1 methyltransferase fused with the GST protein on the N-terminus and a His-rich polypeptide (GHHHHHH) on the C-terminus (GST-HEN1FL-His). The protein was purified in a two-step procedure using glutathione-Sepharose and nickel-loaded chelating column chromatography. In preliminary studies, GST-HEN1-FL-His displayed only a slightly lower activity toward the miR173/ miR173* duplex (Supplemental Fig. 1) as compared with HisHEN1-FL, suggesting that the GST fusion at the N-terminus does not significantly interfere with the catalytic activity of the methyltransferase.

Previous bioinformatic (Tkaczuk et al. 2006; Chen 2007) and mutational ( $\mathrm{Yu}$ et al. 2005) analyses suggested the importance of the C-terminal one-third of HEN1 in interactions with the cofactor. To examine the function of this putative methyltransferase domain, we have examined a truncated variant of HEN1, HEN1-M, comprising the C-terminal residues 666-942. The shortened protein started at the first codon of exon 6 in the genomic sequence of HEN1 gene. Analogously to the full-length methyltransferase, we have constructed and affinity-purified two derivatives of the deletion mutant: histidine-tagged His-HEN1-M and double-tagged GST-HEN1-M-His.

All four proteins were prepared essentially free ( $<2 \mathrm{~mol} \%)$ from bound endogenous S-adenosyl-L-methionine.

\section{Steady-state kinetics of the HEN1 methyltransferase}

Kinetic analysis of the full-length protein was performed to characterize the catalytic mechanism and substrate interactions of the HEN1 methyltransferase. A synthetic RNA duplex corresponding to miR173/miR173* from Arabidopsis thaliana (Fig. 2A) was used as a substrate for experiments with His-HEN1-FL. The methylation reaction was monitored by incorporation of $\left[{ }^{3} \mathrm{H}\right]$-methyl groups from tritium-labeled 

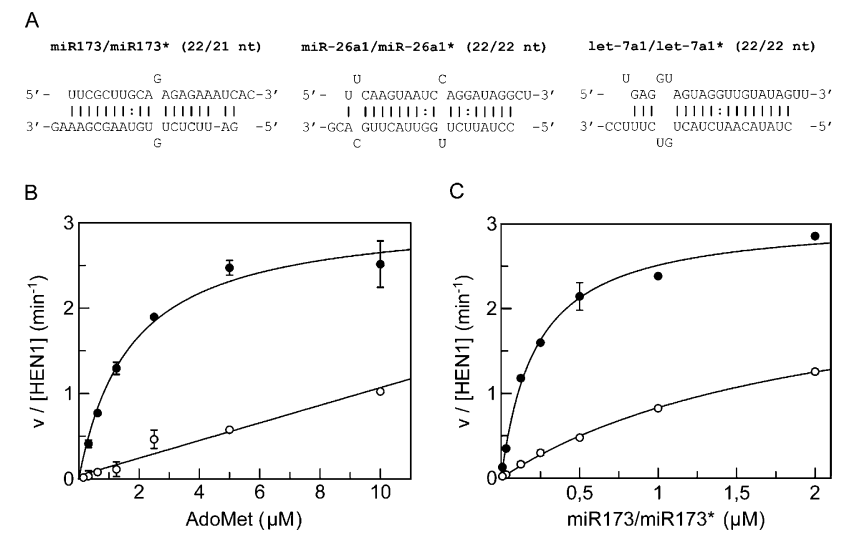

FIGURE 2. Steady-state kinetic analysis of miRNA methylation by HEN1. (A) Structure of miR173/miR173*, miR-26a1/miR-26a ${ }^{*}$, and let-7a1/let-7a1* duplexes used for enzymatic studies. (top strand) miRNA, (bottom strand) miRNA*. $(B, C)$ Methylation velocities determined by incorporation of $\left[\right.$ methyl $\left.-{ }^{3} \mathrm{H}\right]$ groups into RNA substrates by HEN1-FL $(\bullet)$ or HEN1-M $(O)$ in the presence of varied concentrations of miRNA and constant $\left[\right.$ methyl $\left.-{ }^{3} \mathrm{H}\right]$-AdoMet $(B)$ or varied concentrations of AdoMet and constant miR173/miR173* (C). Reactions were incubated for $30 \mathrm{~min}$ at $37^{\circ} \mathrm{C}$. Kinetic parameters were derived by nonlinear fitting of the velocity data (shown by lines) to a Michaelis-Menten equation.

AdoMet into RNA (Yang et al. 2007). The product formation was linear for $\sim 45$ min under our experimental conditions (Supplemental Fig. 2) with up to 14 nM HEN1 (data not shown). All steady-state reactions were performed using a 3.4 nM enzyme and 30-min incubation time (Fig. 2B,C; Table 1). Substrate RNA concentrations were varied from 0.078 to 2 $\mu \mathrm{M}$ in the presence of constant $20 \mu \mathrm{M}$ AdoMet, while $K_{\mathrm{M}}{ }^{\text {AdoMet }}$ measurements were carried out with $2 \mu \mathrm{M}$ RNA and AdoMet ranging from 0.125 to $20 \mu \mathrm{M}$. Nonlinear fitting of multiple-turnover data to hyperbolic equations revealed Michaelis constants for microRNA $\left(K_{\mathrm{M}}{ }^{\mathrm{RNA}}=0.22 \mu \mathrm{M}\right)$ and cofactor $\left(K_{\mathrm{M}}{ }^{\text {AdoMet }}=1.7 \mu \mathrm{M}\right)$ and an apparent catalytic turnover rate $\left(k_{\text {cat }}\right)$ of $3.0 \mathrm{~min}^{-1}$.

\section{C-terminal domain of HEN1 (residues 666-942) is sufficient for methylation}

Similar time course and dose dependence experiments showed that the truncated HEN1-M protein is stable and linear at least during the first $60 \mathrm{~min}$ under the reaction conditions (Supplemental Fig. 2). Preliminary comparison showed that the catalytic activity of the truncated protein was two- to threefold lower compared with the full-length protein under the same reaction conditions with $20 \mu \mathrm{M}$ AdoMet, $2 \mu \mathrm{M} \mathrm{miR173/miR173*}{ }^{*} \mathrm{RNA}$, and $10 \mathrm{nM}$ and $3.4 \mathrm{nM}$ concentrations of HEN1-M or HEN1-FL, correspondingly (Supplemental Fig. 1). Similar steady-state kinetic analysis (Fig. 2B,C; Table 1) showed that HEN1-M has an $\sim 10$-fold higher $K_{\mathrm{M}}{ }^{\mathrm{RNA}}(2.1 \pm 0.2 \mu \mathrm{M}$ for HEN1-M versus $0.2 \pm 0.1 \mu \mathrm{M}$ for HEN1-FL). The $K_{\mathrm{M}}{ }^{\text {AdoMet }}$ could not be defined, since at a $20 \mu \mathrm{M}$ cofactor, the velocity curve was still in a nearly linear phase, indicating that the reaction cannot be sufficiently saturated at practically attainable [methyl- $\left.{ }^{3} \mathrm{H}\right]$ AdoMet concentrations. Nevertheless, our results clearly indicate that the truncated enzyme has a much higher value of $K_{\mathrm{M}}{ }^{\text {AdoMet }}$ than the full-length HEN1. Although the truncated and full-length proteins showed considerable differences in their substrate interactions, the apparent turnover rate $\left(k_{\text {cat }}\right)$ seems to be quite similar. Altogether, the poorer catalytic parameters of the truncated enzyme indicate that the $\mathrm{N}$-terminal domain of HEN1 plays an important role in assembling a catalytically competent reaction complex.

\section{Modification of individual strands in RNA duplexes}

Previous studies found that modification of microRNA duplexes by HEN1 methyltransferase can occur on either strand (Yu et al. 2005; Yang et al. 2006). However, miRNA/ miRNA ${ }^{\star}$ substrates used in these experiments contained structural alterations on one strand of the duplex: atypical 1- or 3-nt overhangs at the $3^{\prime}$-terminus of the complementary strand (Yang et al. 2006) or missing $2^{\prime}$-hydroxyl in the 3 '-terminal nucleotide (Yu et al. 2005). Since unnatural substrates might potentially affect the nature of the proteinRNA interaction, we performed analogous experiments with synthetic RNA structurally identical to the $\mathrm{miR} 173 / \mathrm{miR} 173^{*}$ from A. thaliana.

The modification level of a particular strand by HEN1 was monitored by the sodium periodate cleavage approach (Yang et al. 2007) using duplex RNA ${ }^{33} \mathrm{P}$-labeled on $5^{\prime}$-termini of either the guide or the passenger strand. The results displayed in Figure 3 show that neither miR173 nor miR $173^{*}$ strand is sensitive to sodium periodate treatment, confirming the assumption that both strands of $\mathrm{miR} 173 / \mathrm{miR} 173^{\star}$ are fully methylated. This experiment excludes the possibility that the reaction products present a mixture of differently hemimethylated RNA duplexes. Moreover, similar experiments with both types of reciprocal hemimethylated duplex RNAs (miR173M/miR173* with methylated guide and miR173/ miR173* $\mathrm{M}$ with methylated passenger miR173*), turned fully modified after incubation with HEN1 (data not shown). Our results indicate that methylation of the 3 '-terminal nucleotide on one strand does not preclude the reaction on

TABLE 1. Steady-state kinetic parameters of HEN1 methyltransferase variants

\begin{tabular}{lcc}
\hline Parameter & HEN1-FL & HEN1-M \\
\hline$k_{\text {cat, }} \min ^{-1}$ & $3.0 \pm 0.1$ & $>1$ \\
$K_{\mathrm{M}}{ }^{\mathrm{RNA}} \mu \mathrm{M}$ & $0.22 \pm 0.02$ & $2.1 \pm 0.2$ \\
$K_{\mathrm{M}}{ }^{\text {AdoMet }}{ }^{\prime} \mu \mathrm{M}$ & $1.7 \pm 0.3$ & $>20$ \\
$k_{\text {cat }} / K_{\mathrm{M}}{ }^{\text {RNA }}, \mu \mathrm{M}^{-1} \mathrm{~min}^{-1}$ & 13.6 & $<0.5$ \\
$k_{\text {cat }} / K_{\mathrm{M}}{ }^{\text {AdoMet }}, \mu \mathrm{M}^{-1} \mathrm{~min}^{-1}$ & 1.8 & \\
\hline
\end{tabular}




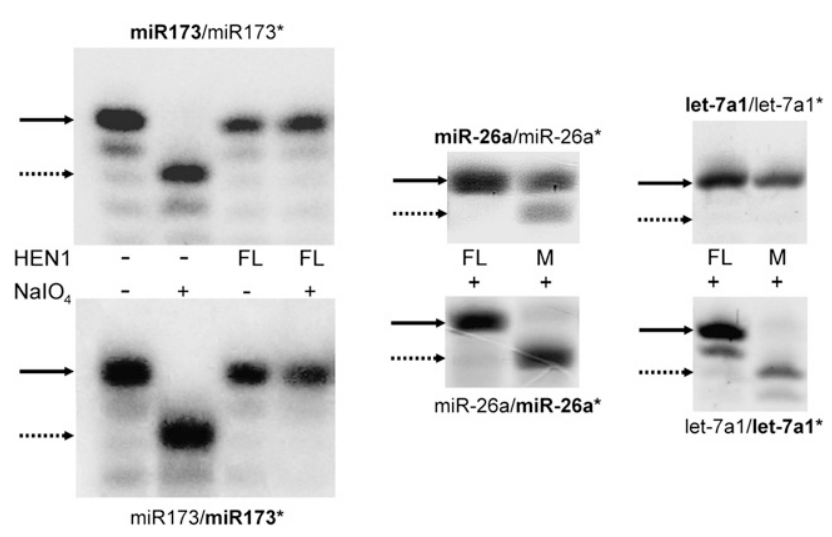

FIGURE 3. Methylation of individual strands in miRNA duplexes by HEN1. Double-stranded microRNA $(0.2 \mu \mathrm{M}) 5^{\prime} \mathrm{L}^{33} \mathrm{P}$-labeled on one strand was incubated with $1 \mu \mathrm{M}$ HEN 1 and $100 \mu \mathrm{M}$ AdoMet for $60 \mathrm{~min}$ at $37^{\circ} \mathrm{C}$ and then treated with $\mathrm{NaIO}_{4}$ and analyzed by denaturating gel electrophoresis/autoradiography. $2^{\prime}$-O-methylation of the 3-terminal nucleotide is observed as protection against removal of the 3-terminal nucleoside on a $5^{\prime}{ }^{33} \mathrm{P}$-labeled strand of a microRNA duplex due to $\mathrm{NaIO}_{4}$ treatment. Solid arrows point at bands corresponding to fulllength RNA strands; dotted arrows point at truncated (unmethylated) RNA strands. Modification of individual labeled strands (indicated in boldface letters) with full-length HEN1-FL or C-terminal domain HEN1-M is shown for $\mathrm{miR} 173 / \mathrm{miR} 173^{*}, \mathrm{miR}-26 \mathrm{a} / \mathrm{miR}-26 \mathrm{a}^{*}$, and let7a1/let-7a1 ${ }^{\star}$ duplexes.

another strand, and thus HEN1 can methylate both strands on a microRNA duplex to completion.

Analogous experiments were carried out using human $\mathrm{miR}-26 \mathrm{a} / \mathrm{miR}-26 \mathrm{a}^{*}$ and let-7a1/let-7a1* with structural features of double-stranded miRNA remarkably differing from $\mathrm{miR} 173 / \mathrm{miR} 173^{\star}$. While nucleotides of one terminus of these duplexes exhibited classical Watson-Crick base pairing, the other end contained pyrimidine-pyrimidine mispairs at the $5^{\prime}$-terminal of the second position, respectively (Fig. 2A). Our experiments demonstrated that both strands of the miR-26a and let-7a1 duplexes were completely modified upon treatment with the full-length enzyme (Fig. 3 ), suggesting that base-pairing alterations even at the ends of RNA duplexes do not disrupt the activity of the HEN1 methyltransferase.

Similarly to the full-length protein, HEN1-M methylated both strands of the miR173/miR173* duplex (data not shown) as well as the $3^{\prime}$-terminal nucleotides of the miR-26a and let-7a1 strands in the other duplexes (Fig. 3, upper). Notably, the methylation activity of HEN1-M on the opposite miR$26 \mathrm{a}^{*}$ or let-7a $1^{\star}$ strands, whose target $3^{\prime}$ nucleotides lie at the mispaired ends of the RNA duplexes, was barely detectable under the same reaction conditions (Fig. 3, bottom). Since the identity of the 3 '-terminal nucleotides in the methylated (C, G, $\mathrm{U}$ ) and resistant $(\mathrm{C}, \mathrm{G})$ RNA strands was quite similar, we conclude that the structure of adjacent base pairs rather than the nature of the $3^{\prime}$-terminal nucleotide is the decisive factor for the methyltransferase activity of the standalone catalytic domain.

\section{Single-stranded versus double-stranded RNA modification by HEN1-M}

All known small silencing RNA methyltransferases share a highly conserved catalytic methyltransferase domain (Chen 2007). However, unlike piRNA or scnRNA modifying enzymes, HEN1 possesses an extended $\mathrm{N}$-terminal part that contains several motifs for RNA binding-two doublestranded RNA binding and La-type winged helix-turn-helix motif domains (Fig. 1). It should be noted that the shorter methyltransferases typically modify single-stranded RNA substrates ranging from 16 to $40 \mathrm{nt}$ in length (Kirino and Mourelatos 2007a; Saito et al. 2007; Kurth and Mochizuki 2009), while the multidomain plant methyltransferase HEN1 prefers RNA duplexes of exactly 21-24 nt (Yang et al. 2006). Since the deletion of N-terminal domain in HEN1-M is structurally similar to the piRNA methyltransferases, it was interesting to examine whether the truncated protein is capable of recognizing single-stranded substrates.

As single-stranded RNA is more sensitive to nuclease contaminations, double-tagged GST-HEN1-FL-His and GSTHEN1-M-His proteins were used in these experiments. RNA methylation assays were performed with 21-nt miR173, 22-nt miR173*, and 28-nt piR3-28A. The first two sequences represent individual strands of the $\mathrm{miR} 173 / \mathrm{miR} 173^{\star}$ duplex; piR3-28A was reported as a preferential substrate for the mouse piRNA methyltransferase mHEN1 (Kirino and Mourelatos 2007a). Identical electrophoretic mobility of the RNA oligonucleotides observed under native and denaturing conditions in control experiments (Supplemental Fig. 3) indicated that they did not form stable double-stranded structures under the reaction conditions. The modification level of a particular strand by HEN1 was first monitored by a sodium periodate cleavage approach (Yang et al. 2007) using ${ }^{33} \mathrm{P}-5^{\prime}$-labeled strands. In single enzyme turnover experiments with $0.4 \mu \mathrm{M}$ RNA targets (or $0.2 \mu \mathrm{M}$ miRNA/miRNA* duplex) and $1 \mu \mathrm{M}$ enzyme, the full-length methyltransferase did not show significant activity on the miR173 strand (Fig. 4A). However, the methylation of miR173* was detectable in the presence of a larger excess of HEN1, which differs from observations by $\mathrm{Yu}$ et al. (2005). HEN1-M showed significant modification of miR173* but no activity with miR173. Experiments with piR3$28 \mathrm{~A}$ revealed a substantial difference between the full-length and the truncated protein: no detectable activity with GSTHEN1-FL-His at protein concentration as high as $4 \mu \mathrm{M}$, but a clearly discernable activity with GST-HEN1-M-His.

Similar experiments were performed by measuring the transfer of labeled methyl groups under steady-state conditions. The data presented in Figure 4B and Supplemental Table 1 indicate that neither the full-length nor the truncated methyltransferase manifested a considerable activity on singlestranded miR173 or piR3-28A. However, HEN1-M retained significant methylation of the miR $173^{\star}$ substrate $(10 \%$ and $24 \%$ relative to the activity of HEN1-FL or HEN1-M on double-stranded miR173/miR173*, respectively). Since the 
A

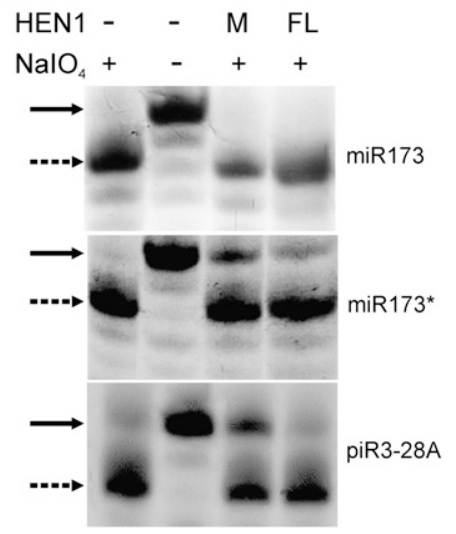

B

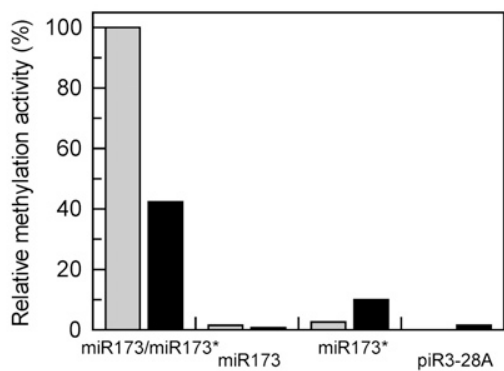

FIGURE 4. Enzymatic activities of HEN1 toward double-stranded and single-stranded RNAs. (A) $5^{\prime}{ }^{33} \mathrm{P}$-labeled RNA strands $(0.2 \mu \mathrm{M})$ were incubated with $1 \mu \mathrm{M}$ HEN1 and $100 \mu \mathrm{M}$ AdoMet for $60 \mathrm{~min}$ at $37^{\circ} \mathrm{C}$ and then treated with $\mathrm{NaIO}_{4}$ and analyzed by denaturating gel electrophoresis/autoradiography. 2'-O-methylation of the 3-terminal nucleotide is observed as protection against removal of the 3 -terminal nucleoside on a $5^{\prime}{ }^{33} \mathrm{P}$-labeled strand of a microRNA duplex due to $\mathrm{NaIO}_{4}$ treatment. Solid arrows point at bands corresponding to fulllength RNA strands; dotted arrows point at truncated (unmethylated) RNA strands. FL denotes full-length HEN1-FL; M denotes truncated HEN1-M. (B) Activity of HEN1-FL and HEN1-M toward single-stranded substrates under steady-state conditions expressed as percentage of the methylation turnover rate of GST-HEN1-FL-His with double-stranded miR173/miR173* duplex. Methylation reactions were performed with $5 \mathrm{nM}$ HEN1-FL (gray bars) or $10 \mathrm{nM}$ HEN1-M (solid bars), $20 \mu \mathrm{M}$ AdoMet and $2 \mu \mathrm{M}$ RNA. activity of the full-length protein on the same single-stranded substrate is only $2.6 \%$ of that observed with the miR $173 /$ miR173* duplex, it is clear that, at least in certain cases, the $\mathrm{N}$-terminal domain enhances the enzyme's specificity toward double-stranded RNA. However, the observed discrimination against single-stranded substrates by HEN1-M clearly shows that the catalytic domain itself carries most of the structural determinants necessary for the selective recognition and methylation of RNA duplexes.

\section{Dissection of the catalytic step in HEN1 methyltransferase}

To assess the contribution of individual steps in the reaction cycle, kinetic experiments under single turnover conditions $([\mathrm{E}]>[\mathrm{S}]$ ) were performed. In the first series, doublestranded $\mathrm{miR} 173 / \mathrm{miR} 173^{\star} \mathrm{RNA}$ and an excess of HEN1 was rapidly mixed with tritium labeled AdoMet as the cofactor (Fig. 5, solid line), and the reaction was quenched at specified time points using a rapid quench device. A single exponential approximation of the time course gave a rate of $2.0 \pm 0.1$ $\min ^{-1}$ for the apparent methyltransfer step. All structural information available identifies only one catalytic site in HEN1 (Yu et al. 2005; Tkaczuk et al. 2006; Huang et al. 2009), and therefore the methyltransferase modifies only one strand of a bound RNA duplex. Modification of the other strand requires a repeat binding of the duplex in the opposite orientation. Therefore, the obtained kinetic parameter is not purely that of a single turnover reaction but rather derives from the modification rates of the two individual strands in the duplex. To determine the modification rate of each individual strand we have performed similar experiments with hemimethylated RNA duplexes (Fig. 5). The reaction profiles for hemimethylated RNA duplexes showed twofold lower amplitudes and slightly higher rates $\left(k_{\mathrm{ST}}{ }^{\mathrm{miR173} / \mathrm{miR}^{\mathrm{R}} 173^{*} \mathrm{M}}=\right.$ $3.2 \pm 0.4 \mathrm{~min}^{-1} ; k_{\mathrm{ST}}{ }^{\mathrm{miR} 173 \mathrm{M} / \mathrm{miR} 173^{*}}=$ $5.7 \pm 0.8 \mathrm{~min}^{-1}$ ) compared with the unmethylated duplex substrate. Notably, the aggregate rate derived from two consecutive reactions with velocities corresponding to $k_{\mathrm{ST}}{ }^{\mathrm{miR} 173 / \mathrm{miR} 173^{*} \mathrm{M}}$ and $k_{\mathrm{ST}}{ }_{\mathrm{miR} 173 \mathrm{M} / \mathbf{m i R}^{2}{ }^{*}}$ would be equal $1 / k_{\mathrm{obs}}=$ $1 / k^{\mathbf{m i R} 173 / \mathrm{miR} 3^{*} \mathrm{M}}+1 / k^{\mathrm{miR} 173 \mathrm{M} / \mathbf{m i R}^{\mathrm{mi73}}{ }^{\star}}=$ $2.1 \mathrm{~min}^{-1}$, which matches well the rate of methylation of the unmethylated duplex. Altogether, these results are consistent with a mechanism whereby HEN1-dependent methylation of each strand in a miRNA duplex occurs independently and that incorporation of a methyl group of one strand has little or no effect on the methylation of the other.

Moreover, the rates obtained under single turnover conditions $([\mathrm{E}]>[\mathrm{S}]$ ) (Fig. 5) are comparable with the overall catalytic rate $\left(k_{\mathrm{cat}}=3.0 \mathrm{~min}^{-1}\right)$ determined in steadystate experiments $([\mathrm{E}]<[\mathrm{S}])$ with the same unmethylated double-stranded miR173/miR173*. Since the multiple turnover rate includes contributions from the rate of enzyme dissociation, it is clear that the formation of the catalytic complex or the transfer of the methyl group should be the rate-limiting event of the reaction, or at least the dissociation

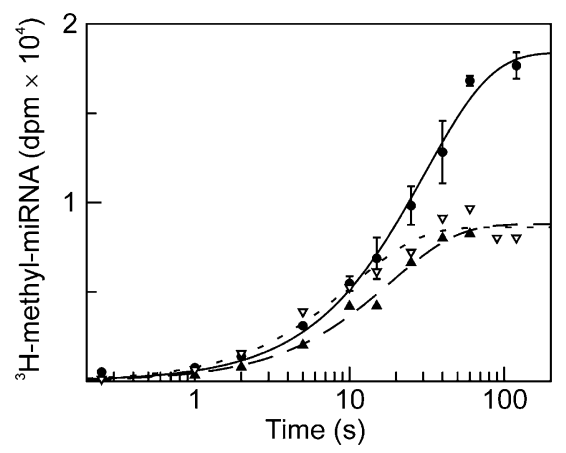

FIGURE 5. Single-turnover kinetics of microRNA methylation by HEN1. Premixed $0.1 \mu \mathrm{M}$ unmethylated $\operatorname{miR} 173 / \mathrm{miR} 173^{*}(\bullet)$ or hemimethylated miR173M/miR173* $(\nabla)$ or miR173/miR173* ${ }^{*}(\mathbf{\Delta})$ microRNA and $1 \mu \mathrm{M}$ HEN1-FL were rapidly mixed with $10 \mu \mathrm{M}$ [methyl- $\left.{ }^{3} \mathrm{H}\right]$-AdoMet at $37^{\circ} \mathrm{C}$ in a rapid-quench device. Reactions were quenched in a timely manner and processed using DE-81 filter binding. Time course of $\left[\right.$ methyl- $\left.{ }^{3} \mathrm{H}\right]$ incorporation was analyzed by fitting to a single exponential equation to give single turnover rates of $2.0 \pm 0.1$ $\min ^{-1}, 5.7 \pm 0.8 \mathrm{~min}^{-1}$ and $3.2 \pm 0.4 \mathrm{~min}^{-1}$, respectively. 
of the HEN1•AdoHcy•methylated RNA complex is not considerably slower.

\section{DISCUSSION}

To date, HEN1 remains the sole characterized representative of 2'-O-methyltransferases that modify double-stranded microRNA and siRNA. Although sequence database searches reveal novel putative HEN1 homologs in a variety of plant species, from moss to flowering plants (Huang et al. 2009; C Venclovas, pers. comm.), there is no direct experimental evidence that the identified genes encode catalytically active proteins. Our analyses thus provide the first kinetic insight into the mechanism of action, domain interplay, and catalytic function of this important enzyme. Since the determined kinetic parameters $\left(k_{\mathrm{cat}}\right.$ and $\left.K_{\mathrm{M}}\right)$ are not particularly different from those of other characterized functional AdoMet-dependent RNA methyltransferases, it is fair to suggest that HEN1 is capable of efficient miRNA methylation unassisted by any supplementary cellular proteins in vivo.

Naturally, the silencing complex is assembled by incorporation of a methylated miRNA/miRNA* duplex in an asymmetric manner: one strand of the duplex (to become the guide strand) is preferentially incorporated into RISC, while the other (passenger) strand is degraded. The mechanism of the target strand selection is not fully understood. The thermostability of the $5^{\prime}$ end of the duplex and the nature of the 5 '-terminal nucleotide has been proposed to specify the selection of the guide strand by different types of Argonaute proteins ( $\mathrm{Mi}$ et al. 2008; Eamens et al. 2009). Since the methylation of the miRNA/miRNA* duplex by HEN1 immediately precedes its incorporation into RISC, a functional role of the methylation for the guide strand selection by the Argonaute proteins cannot be excluded. It was demonstrated that either strand of a microRNA duplex could be $2^{\prime}$ $\mathrm{O}$-methylated at the $3^{\prime}$-termini by HEN1 in vitro ( $\mathrm{Yu}$ et al. 2005; this study). Our data using microRNA (Fig. 3) or siRNA (A Plotnikova, unpubl.) indicate that complete modification occurs on both strands of the RNA duplexes regardless of the primary or secondary structure of their $5^{\prime}$-termini. The observed differences in the methylation rates of individual strands of miRNA duplexes in vitro are clearly insufficient to generate substantial bias of specifically hemimethylated miRNA species. Overall, the presented evidence suggests that the HEN1-dependent methylation per se is unlikely to govern the guide strand preference in the plant silencing complex. Nevertheless, it is possible that some other proteins interacting with HEN1 contribute to the strand polarity of methylation in vivo thereby mediating the strand discrimination in RISC.

Several short RNA methyltransferases that share similar catalytic domains with HEN1 have been shown to modify piRNAs substrates in Drosophila, mouse, and human germ cells (Horwich et al. 2007; Kirino and Mourelatos 2007a; Saito et al. 2007; Mui Chan et al. 2009). Unlike HEN1, which acts on RNA duplexes (Fig. 4), the other HEN1 homologs methylate single-stranded RNA substrates in vitro. These considerations suggest that one role of the N-terminal domains in HEN1 is to confer the specificity for duplex RNA. Inspection of available crystal structures indicates that the $\mathrm{N}$-terminal part of the protein indeed extends multiple interactions that serve to accommodate an RNA duplex of a particular helical pitch. On the other hand, our functional studies of HEN1-M indicate that the minimal catalytic domain alone was comparably active toward microRNAs in the absence of the $\mathrm{N}$-terminal domain. A strong preference of HEN1-M toward RNA duplexes thus sets it apart from the other HEN1 homologs.

The determinants involved in the substrate discrimination by HEN1-M are not immediately obvious. Examination of the X-ray structures shows no direct hydrogen bond interactions to the nontarget strand from the C-terminal catalytic domain other than a hydrogen bond between the side chain of S747 and the $5^{\prime}$-phosphate. Three positively charged side chains of the K749, R753, and K756 residues are directed toward the major groove of the dsRNA and presumably enhance the 5 ' -phosphate interaction (Huang et al. 2009). However, since they do not form direct contacts with the backbone phosphates of the nontarget strand, the roles of these amino acids for HEN1-M selectivity toward doublestranded RNA may hardly be considerable. On the other hand, our kinetic analyses show that the deletion of the N-terminal part of HEN1 is reflected in changes of $K_{\mathrm{M}}$ for both substrates rather than $k_{\text {cat }}$. This suggests that the methylation activity is under a certain control of the $\mathrm{N}$-terminal domain, but it mostly affects binding of substrates but not the positioning of critical residues (the 2 '-hydroxyl of the target 3 '-terminal nucleotide and the methyl group of AdoMet) in the catalytic center. Thus the catalytic domain is somehow capable of binding dsRNA substrates in a correct orientation for catalysis. The apparent discrepancy can be resolved if the bound helix is considered as a single structural unit in which both strands cooperate in maintaining proper conformations of the reactants in the catalytic center (substrate-assisted catalysis) (see Fig. 6).

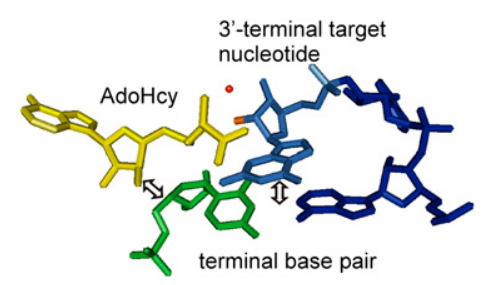

FIGURE 6. Stick representation of the reaction center of the HEN1 methyltransferase. Cofactor AdoHcy is yellow, the target 2'-hydroxyl is orange, three $3^{\prime}$-terminal nucleotides of the target RNA strand are dark blue, and the $5^{\prime}$-terminal nucleotide of the nontarget strand is green; catalytic $\mathrm{Mg}^{2+}$ is shown as a red ball. Protein residues are omitted for clarity. White arrows indicate van der Waals and stacking interactions from the terminal base pair of the RNA duplex that are implicated in defining proper catalytic conformations of the cofactor and the target nucleotide. 
Indeed, stacking interactions of the terminal base pair of the duplex with the target nucleotide and the bound AdoMet cofactor appear critical for aligning the methyl for transfer onto the 2'-hydroxyl of the target 3 '-terminal nucleotide. Therefore, although direct contacts of the catalytic domain with the nontarget strand is not critically important for the preferential methylation of double-stranded RNA, a proper base pairing of the terminal nucleotides is obligatory for the assembly of the catalytic center and correct arrangement of the cofactor and target nucleotide. Indeed, our study shows that HEN1-M was functional on all RNA targets that contained complementary base pairs at the first and second positions but was much less efficient in cases with mispaired nucleotides at these positions (Fig. 3). On the other hand, the full-length protein appears largely insensitive to such structural deviations in the RNA helix, since the N-terminal domain assists in stable binding of the duplex and thereby enhancing intrahelical conformations of the terminal mispaired nucleotides in the reaction complex.

\section{MATERIALS AND METHODS}

\section{Construction of recombinant plasmids carrying HEN1 and its truncated form}

Plasmids pET-HEN1 and pGEX-HEN1 containing the full-length methyltransferase from $A$. thaliana were constructed as described previously (Yang et al. 2007). The 931-base-pair (bp) DNA fragment encoding the C-terminal domain of HEN1 (the HEN1 fragment including amino acids 666-942) was obtained from the plasmid pET-HEN1 by PCR with the primers 5'-GGGTTATGCT AGTTATTGC-3' and 5'-CGCTCGCATATGTCAGAACGTCCAT GTTTA-3', digested with Bpu1102I and NdeI and ligated to 5617-bp fragment of pET-HEN1 that had been restricted with Bpu1102I and NdeI, resulting in plasmid pET-HEN1-M.

To construct the wild-type HEN1 fused with both HisTag and GST-GST-HEN1-His, the full-length HEN1 coding region was amplified with primers $5^{\prime}$-CACGATGAATTCTCAGTGATGATGAT GATGATGGCCAAGATCAGTCTTTTTCT- ${ }^{\prime}$ and 5' -AGCAAGT ATATAGCATGG-3' from pGEX-HEN1 (Yang et al. 2007). The 2988-bp PCR product was digested by EcoRI to form 2858-bp fragment and ligated to SAP-treated 4969-bp product of pGEXHEN1 digestion by EcoRI. To create a deletion mutant HEN1-M joined with GST protein N-terminal end and HisTag on C-terminal end named GST-HEN1-M-His, a 1215-bp fragment harboring the C-terminal domain of HEN1 was released from pET-HEN1-M using NdeI and AatII (all enzymes for cloning were bought from UAB Fermentas) and ligated to a 4691-kb fragment obtained from pGEX-HEN1 digestion with NdeI and AatII.

\section{Expression and purification of HEN1 methyltransferases}

Purification of His-HEN1 and His-HEN1-M was performed as described previously (Yang et al. 2007) with modifications. In brief, the recombinant clones were transformed into $E$. coli BL21(DE3)RIL (Invitrogen), and protein expression was induced with $0.1 \mathrm{mM}$ IPTG at $16^{\circ} \mathrm{C}$ overnight. The cell pellet was resuspended in $50 \mathrm{mM}$ phosphate buffer with $10 \%$ sucrose, $1 \mathrm{M}$ $\mathrm{NaCl}, 0.1 \%(\mathrm{v} / \mathrm{v})$ Triton $\mathrm{X}-100,1 \mu \mathrm{M}$ pepstatin, and Complete EDTA-free Protease Inhibitor Cocktail tablets (Roche Applied Science). Lysed cells were centrifuged at 25,000 rpm for $10 \mathrm{~min}$. The supernatant was filtered through a $0.45 \mu \mathrm{M}$ Rotilabo PVDF filter (Carl Roth) and then loaded onto a $5 \mathrm{~mL}$ HiTrap Helating Sepharose HP (Amersham Pharmacia Biosciences), equilibrated with buffer A (50 mM phosphate buffer at $\mathrm{pH} 6.2$, with $10 \%$ sucrose, $1 \mathrm{M} \mathrm{NaCl}, 3 \mathrm{mM} \mathrm{MgCl}, 0.1 \%$ [v/v] Triton X-100, $5 \mathrm{mM}$ 2-mercaptoethanol). His-tagged proteins were eluted with buffer B (50 mM phosphate buffer at $\mathrm{pH} 6.2$, with $10 \%$ sucrose, $1 \mathrm{M}$ $\mathrm{NaCl}, 3 \mathrm{mM} \mathrm{MgCl}_{2}, 1 \mathrm{M}$ imidazole, $0.1 \%$ [v/v] Triton X-100, $5 \mathrm{mM}$ 2-mercaptoethanol). Fractions, containing the target protein were collected, concentrated, and loaded in Slide-A-lyzer Dialysis Cassette $10000 \mathrm{MWCO}, 0.5-3 \mathrm{~mL}$ (Pierce) and dialyzed three times against buffer $\mathrm{A}$ for at least $3 \mathrm{~h}$ each and for $4 \mathrm{~h}$ against $50 \mathrm{mM}$ phosphate buffer at $\mathrm{pH} 7.4$, with $0.25 \mathrm{mM} \mathrm{NaCl}, 50 \%(\mathrm{v} / \mathrm{v})$ glycerol, $0.1 \%(\mathrm{v} / \mathrm{v})$ Triton X-100, and $5 \mathrm{mM}$ 2-mercaptoethanol.

The double-tagged full-length GST-HEN1-His and truncated GST-HEN1-M-His were first purified on a nickel-loaded HiTrap chelating Sepharose HP (Amersham Pharmacia Biosciences) as described above, then fractions were collected and loaded on a GSTrap chelating Sepharose HP (GE Healthcare), equilibrated with $50 \mathrm{mM}$ phosphate buffer at $\mathrm{pH} 7.2$, with $10 \%$ sucrose, $1 \mathrm{M}$ $\mathrm{NaCl}, 3 \mathrm{mM} \mathrm{MgCl}_{2}, 0.1 \%$ (v/v) Triton X-100, and $5 \mathrm{mM}$ 2-mercaptoethanol. Proteins were eluted with $10 \mathrm{mM}$ reduced glutathione in $50 \mathrm{mM}$ phosphate buffer at $\mathrm{pH} 7.2$, with $10 \%$ sucrose, $1 \mathrm{M} \mathrm{NaCl}, 3 \mathrm{mM} \mathrm{MgCl} 2,0.1 \%$ (v/v) Triton X-100, and $5 \mathrm{mM}$ 2-mercaptoethanol. Target fractions were dialyzed as described above and then stored at $-20^{\circ} \mathrm{C}$.

\section{RNA methylation assay using periodate oxidation method}

Methylation activity of HEN1 with unlabeled AdoMet was studied by the periodate oxidation method (Yang et al. 2007). Methyltransferase reactions were carried out essentially as described previously (Yang et al. 2007) with a 1-4 $\mu$ M HEN1, $100 \mu \mathrm{M}$ AdoMet, and 0.2 $\mu \mathrm{M}$ RNA duplex in which one strand was $5^{\prime}$-phosphorylated using $\left[\gamma^{3}{ }^{33} \mathrm{P}\right]$ ATP (Hartmann Analytic). Single-stranded RNA modification was studied using $0.2 \mu \mathrm{M}$ miR173, miR173*, or piR3-28A. Following periodate treatment, the reaction products were resolved on $15 \%$ polyacrilamide gel with urea under denaturing conditions and then analyzed by phosphorescention using FLA-5100 Image Reader (Fujifilm) and MultiGauge V3.0 software.

\section{Enzymatic activity assays}

Steady-state methylation reactions were typically carried out at $37^{\circ} \mathrm{C}$ for $30 \mathrm{~min}$ in $25 \mu \mathrm{L}$ of Reaction buffer $(10 \mathrm{mM}$ Tris- $\mathrm{HCl}$ at $\mathrm{pH} 7.5,50 \mathrm{mM} \mathrm{NaCl}, 0.4 \mu \mathrm{M}$ DTT, $0.1 \mathrm{mg} / \mathrm{mL}$ bovine serum albumin) with $3.43 \mathrm{nM}$ HEN1, $20 \mu \mathrm{M}$ [methyl $\left.-{ }^{3} \mathrm{H}\right]$ AdoMet $(5.65$ $\mathrm{Ci} / \mathrm{mmol}$, PerkinElmer) and $2 \mu \mathrm{M}$ double-stranded RNA. $K_{\mathrm{M}}{ }^{\text {AdoMet }}$ analysis was performed with $0.125-20 \mu \mathrm{M}$ [methyl $\left.{ }^{3} \mathrm{H}\right]$ AdoMet, $K_{\mathrm{M}}{ }^{\text {RNA }}$ analysis was performed with $0.078-2 \mu \mathrm{M} \mathrm{miR} 173 / \mathrm{miR} 173^{*}$. Reactions were quenched by addition of $0.4 \mathrm{mM}$ unlabeled AdoMet (Sigma-Aldrich) and proteinase K (Fermentas) to a final concentration of $2 \mathrm{mg} / \mathrm{mL}$ in Stop buffer $(40 \mathrm{mM}$ Tris- $\mathrm{HCl}$ at $\mathrm{pH} 7.4$, $1 \mathrm{mM}$ EDTA, $20 \mathrm{mM} \mathrm{NaCl}, 1 \% \mathrm{SDS})$. Reactions with singlestranded RNAs ( $2 \mu \mathrm{M}$ miR173, miR173*, piR3-28A) were performed 
in the presence of $20 \mu \mathrm{M}$ [methyl $\left.{ }^{3} \mathrm{H}\right]$ AdoMet and $5 \mathrm{nM}$ GSTHEN1-FL-His or $10 \mathrm{nM}$ GST-HEN1-7C-His for $30 \mathrm{~min}$ at $37^{\circ} \mathrm{C}$. Samples were spotted onto $2.3-\mathrm{cm}$ DE-81 filters (Whatman), washed four times with $50 \mathrm{mM} \mathrm{Na}-\mathrm{PO}_{4}$ at $\mathrm{pH} 7.0$, twice with $\mathrm{H}_{2} \mathrm{O}$, twice with ethanol, and once with acetone, then air-dried and counted with $4 \mathrm{~mL}$ of Rotiszint Eco lipophylic LSC Cocktail (Carl Roth). Background counts were subtracted. Enzymatic activity was estimated by analyzing data from two to three replicates.

\section{Single-turnover assays}

Methylation reactions under single-turnover conditions were carried out with $1 \mu \mathrm{M}$ of HEN1, $100 \mathrm{nM}$ duplex RNA, and 10 $\mu \mathrm{M}\left[\right.$ methyl $\left.-{ }^{3} \mathrm{H}\right]$-AdoMet in reaction buffer at $37^{\circ} \mathrm{C}$. Reactions were quenched with Stop buffer (1.5\% SDS, 1\% FEN) after specified time periods using a rapid-quench-flow device RQF-3 (KinTek) and processed as described above. Kinetic parameters were obtained by fitting experimental data to a single-exponential equation using computer software GraFit version 5 (Leatherbarrow 2001).

\section{SUPPLEMENTAL MATERIAL}

Supplemental material can be found at http://www.rnajournal.org.

\section{ACKNOWLEDGMENTS}

We are grateful to $\mathrm{X}$. Chen for a gift of the pGEX-2TK-HEN1 plasmid and for comments on the manuscript. We thank D. Kavaliauskas and A. Osipenko for experimental assistance, and C. Venclovas for valuable discussions. This work was supported by grants from the Lithuanian State Science and Studies Foundation (T13-07 to G.V.) and from the Global Grant Programme of the Research Council of Lithuania (VP1-3.1-ŠMM-07-K-01-105 to S.K.), and the COST action BM0703.

Received May 24, 2010; accepted June 30, 2010.

\section{REFERENCES}

Bartel DP. 2009. MicroRNAs: Target recognition and regulatory functions. Cell 136: 215-233.

Brennecke J, Aravin AA, Stark A, Dus M, Kellis M, Sachidanandam R, Hannon GJ. 2007. Discrete small RNA-generating loci as master regulators of transposon activity in Drosophila. Cell 128: 1089-1103.

Carthew RW, Sontheimer EJ. 2009. Origins and mechanisms of miRNAs and siRNAs. Cell 136: 642-655.

Chen X. 2007. A marked end. Nat Struct Mol Biol 14: 259-260.

Eamens AL, Smith NA, Curtin SJ, Wang MB, Waterhouse PM. 2009. The Arabidopsis thaliana double-stranded RNA binding protein DRB1 directs guide strand selection from microRNA duplexes. RNA 15: 2219-2235.

Ghildiyal M, Zamore PD. 2009. Small silencing RNAs: An expanding universe. Nat Rev Genet 10: 94-108.

Gunawardane LS, Saito K, Nishida KM, Miyoshi K, Kawamura Y, Nagami T, Siomi H, Siomi MC. 2007. A slicer-mediated mecha- nism for repeat-associated siRNA $5^{\prime}$ end formation in Drosophila. Science 315: 1587-1590.

Horwich MD, Li C, Matranga C, Vagin V, Farley G, Wang P, Zamore PD. 2007. The Drosophila RNA methyltransferase, DmHen1, modifies germline piRNAs and single-stranded siRNAs in RISC. Curr Biol 17: 1265-1272.

Houwing S, Kamminga LM, Berezikov E, Cronembold D, Girard A, van den Elst H, Filippov DV, Blaser $\mathrm{H}$, Raz E, Moens CB, et al. 2007. A role for Piwi and piRNAs in germ cell maintenance and transposon silencing in zebrafish. Cell 129: 69-82.

Huang Y, Ji L, Huang Q, Vassylyev DG, Chen X, Ma JB. 2009. Structural insights into mechanisms of the small RNA methyltransferase HEN1. Nature 461: 823-827.

Kim VN, Han J, Siomi MC. 2009. Biogenesis of small RNAs in animals. Nat Rev Mol Cell Biol 10: 126-139.

Kirino Y, Mourelatos Z. 2007a. The mouse homolog of HEN1 is a potential methylase for Piwi-interacting RNAs. RNA 13: 1397-1401.

Kirino Y, Mourelatos Z. 2007b. Mouse Piwi-interacting RNAs are 2'-O-methylated at their $3^{\prime}$ termini. Nat Struct Mol Biol 14: $347-348$.

Kurth HM, Mochizuki K. 2009. 2'-O-methylation stabilizes Piwiassociated small RNAs and ensures DNA elimination in Tetrahymena. RNA 15: 675-685.

Leatherbarrow RJ. 2001. GraFit version 5: Data Analysis and Graphics program, v.5.0. Erithacus Software, Horley, UK.

Mi S, Cai T, Hu Y, Chen Y, Hodges E, Ni F, Wu L, Li S, Zhou H, Long C, et al. 2008. Sorting of small RNAs into Arabidopsis argonaute complexes is directed by the $5^{\prime}$ terminal nucleotide. Cell 133: 116127.

Moazed D. 2009. Small RNAs in transcriptional gene silencing and genome defence. Nature 457: 413-420.

Mui Chan C, Zhou C, Brunzelle JS, Huang RH. 2009. Structural and biochemical insights into $2^{\prime}$-O-methylation at the $3^{\prime}$-terminal nucleotide of RNA by Hen1. Proc Natl Acad Sci 106: 17699-17704.

Ohara T, Sakaguchi Y, Suzuki T, Ueda H, Miyauchi K. 2007. The $3^{\prime}$ termini of mouse Piwi-interacting RNAs are 2'-O-methylated. Nat Struct Mol Biol 14: 349-350.

Park W, Li J, Song R, Messing J, Chen X. 2002. CARPEL FACTORY, a Dicer homolog, and HEN1, a novel protein, act in microRNA metabolism in Arabidopsis thaliana. Curr Biol 12: 1484-1495.

Saito K, Sakaguchi Y, Suzuki T, Siomi H, Siomi MC. 2007. Pimet, the Drosophila homolog of HEN1, mediates 2'-O-methylation of Piwiinteracting RNAs at their 3' ends. Genes Dev 21: 1603-1608.

Tkaczuk KL, Obarska A, Bujnicki JM. 2006. Molecular phylogenetics and comparative modeling of HEN1, a methyltransferase involved in plant microRNA biogenesis. BMC Evol Biol 6: 6.

Vagin VV, Sigova A, Li C, Seitz H, Gvozdev V, Zamore PD. 2006. A distinct small RNA pathway silences selfish genetic elements in the germline. Science 313: 320-324.

van Rij RP, Berezikov E. 2009. Small RNAs and the control of transposons and viruses in Drosophila. Trends Microbiol 17: 163171.

Wang XH, Aliyari R, Li WX, Li HW, Kim K, Carthew R, Atkinson P, Ding SW. 2006. RNA interference directs innate immunity against viruses in adult Drosophila. Science 312: 452-454.

Yang Z, Ebright YW, Yu B, Chen X. 2006. HEN1 recognizes 21-24 nt small RNA duplexes and deposits a methyl group onto the $2^{\prime} \mathrm{OH}$ of the 3' terminal nucleotide. Nucleic Acids Res 34: 667-675.

Yang Z, Vilkaitis G, Yu B, Klimasauskas S, Chen X. 2007. Approaches for studying microRNA and small interfering RNA methylation in vitro and in vivo. Methods Enzymol 427: 139-154.

Yu B, Yang Z, Li J, Minakhina S, Yang M, Padgett RW, Steward R, Chen X. 2005. Methylation as a crucial step in plant microRNA biogenesis. Science 307: 932-935. 

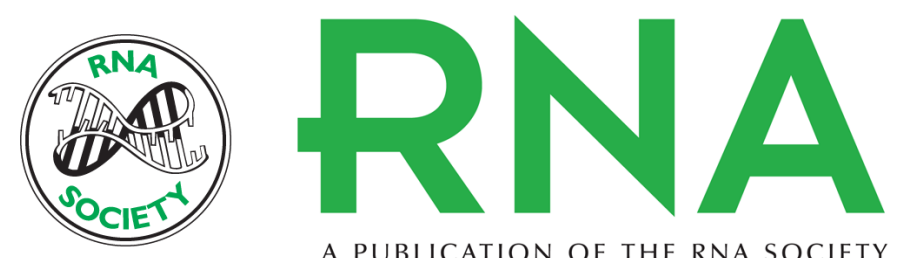

A PUBLICATION OF THE RNA SOCIETY

\section{Kinetic and functional analysis of the small RNA methyltransferase HEN1: The catalytic domain is essential for preferential modification of duplex RNA}

Giedrius Vilkaitis, Alexandra Plotnikova and Saulius Klimasauskas

RNA 2010 16: 1935-1942 originally published online August 12, 2010

Access the most recent version at doi:10.1261/rna.2281410

Supplemental Material

References

License

Email Alerting Service
http://rnajournal.cshlp.org/content/suppl/2010/07/21/rna.2281410.DC1

This article cites 27 articles, 9 of which can be accessed free at: http://rnajournal.cshlp.org/content/16/10/1935.full.html\#ref-list-1

Receive free email alerts when new articles cite this article - sign up in the box at the top right corner of the article or click here. 